\title{
AIAA 2001-2889 \\ Aerothermodynamic \\ Environment Definition for the \\ Genesis Sample Return Capsule
}

\author{
F. McNeil Cheatwood \\ N. Ronald Merski, Jr. \\ Christopher J. Riley \\ Robert A. Mitcheltree
}

NASA Langley Research Center
Hampton, Virginia

$35^{\text {th }}$ AIAA Thermophysics Conference

June 11-14, 2001

Anaheim, CA 

AIAA 2001-2889

\title{
AEROTHERMODYNAMIC ENVIRONMENT DEFINITION FOR THE GENESIS SAMPLE RETURN CAPSULE
}

\author{
F. McNeil Cheatwood. ${ }^{*}$ N. Ronald Merski, Jr., ${ }^{7}$ Christopher J. Riley, ${ }^{+}$Robert A. Mitcheltree \\ NASA Langley Research Center \\ Hampton. Virginia
}

\begin{abstract}
NASA's Genesis sample return mission will be the first to return material from beyond the Earth-Moon system. NASA Langley Research Center supported this mission with aerothermodynamic analyses of the sample return capsule. This paper provides an overview of that effort. The capsule is attached through its forebody to the spacecraft bus. When the attachment is severed prior to Earth entry, forebody cavities remain. The presence of these cavities could dramatically increase the heating environment in their vicinity and downstream. A combination of CFD calculations and wind tunnel phosphor thermography tests were employed to address this issue. These results quantify the heating environment in and around the cavities, and were a factor in the decision to switch forebody heat shield materials. A transition map is developed which predicts that the flow aft of the penetrations will still be laminar at the peak heating point of the trajectory. As the vehicle continues along the trajectory to the peak dynamic pressure point. fully turbulent flow aft of the penetrations could occur. The integrated heat load calculations show that a heat shield sized to the stagnation point levels will be adequate for the predicted environment aft of the penetrations.
\end{abstract}

\section{NOMENCLATURE}

d

depth of cavity [in, $\mathrm{cm}]$

altitude $[\mathrm{km}]$ heat load $\left[\mathrm{J} / \mathrm{cm}^{2}\right]$ heating rate $\left[W / \mathrm{cm}^{2}\right]$ radius [in, $m$ ] Reynolds number cell Reynolds number at wall temperature $[K]$

time $[s]$ velocity $[\mathrm{m} / \mathrm{s}]$ width of cavity $[i n,(m]$ heat transfer coefficient $\left[\mathrm{kg} / \mathrm{m}^{2}-\mathrm{s}\right]$ radial distance from spin axis [in, $m]$

* Vehicle Analysis Branch. Senior Member AIA

'Aerothermodynamics Branch, Associate Fellow AIA A.

Acrothermodynamics Branch. Senior Member $A I A A$

Exploration Fenginering (office, Sonior Member AIA

Copyright $(02001$ by the American Institute of Aeronautics and Astronautics, Inc. No copyright is asserted in the United States under Title 17, U.S. Code. The U.S. Government has a royaltyfree license to exercise all rights under the copyright claimed herein for Governmental Purposes. All other rights are reserved by the copyright owner.

$\begin{array}{ll}\mathrm{z} & \text { axial distance from nose }[\mathrm{in}, \mathrm{m}] \\ \alpha & \text { angle of attack [deg] } \\ \beta & \text { forebody cone half angle }[\mathrm{deg}] \\ \delta & \text { boundary layer thickness }[\mathrm{in} . \mathrm{m}] \\ \varepsilon & \text { surface emissivity } \\ \Theta & \text { momentum thickness }[\mathrm{in}, \mathrm{m}] \\ \theta & \text { angular location of cavity }[\mathrm{deg}] \\ \rho & \text { density }\left[\mathrm{kg} / \mathrm{m}^{3}\right] \\ \tau & \text { cavity taper angle }[\mathrm{deg}]\end{array}$

\section{Subscripts}

b base

c cavity

D maximum diameter of model

e boundary layer edge

FR Fay-Riddell formula

lam laminar

n nose

nom nominal cavity

s shoulder

turb turbulent

w wall

$\infty \quad$ freestream

$\Theta \quad$ momentum thickness 


\section{INTRODUCTION}

The Genesis mission is part of NASA's Discovery Program, which investigates answers to the fundamental questions of the solar system. The objective of Genesis (http://genesismission.jpl.nasa.gov/) is to collect solar wind from the Sun in order to gather information about the origins of the solar system. These are to be the first samples brought back to Earth from beyond the Earth-Moon system.

Set to launch in mid-2001, the Genesis spacecraft (shown in Figure 1) will cruise for three months to a halo orbit about the L1 libration point $(0.01 \mathrm{AU}$ from Earth). There it will deploy collector arrays which will be exposed to solar wind for two years. At the end of that time, the collectors will be stowed in a sample return capsule (SRC), and the spacecraft will return to the Earth. Upon its arrival in 2004, the SRC will separate from the rest of the spacecraft and reenter the atmosphere. decelerating with the aid of a parachute. A helicopter will perform a mid-air recovery over the United States Air Force (USAF) Utah Test and Training Range (UTTR).

A drawing of the Genesis SRC geometry is presented in Figure 2, and its defining parameters are given in Table 1. Its forebody (a spherically-blunted cone with a rounded shoulder) is similar to that of the Star-

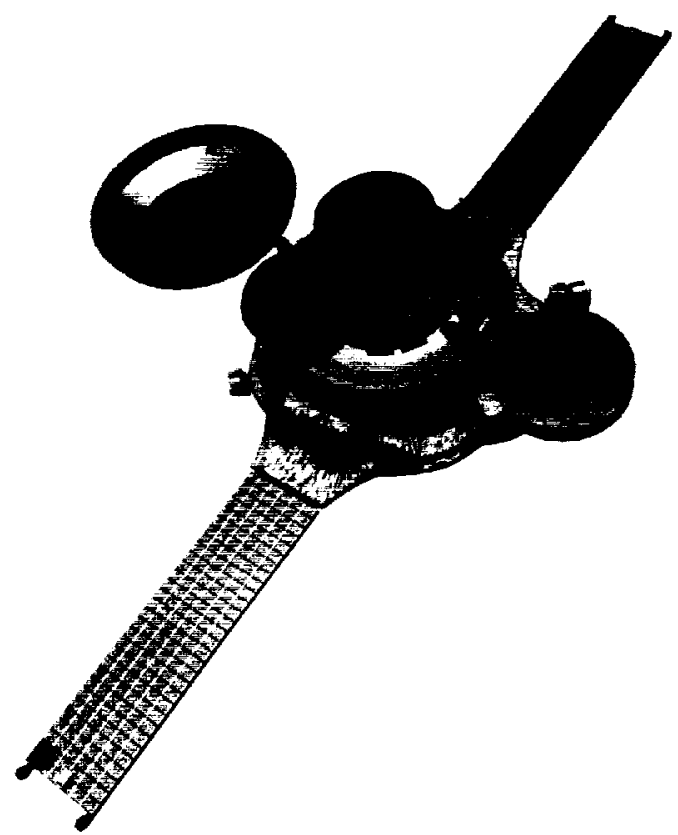

Figure 1. Genesis spacecraft with collector arrays deployed.

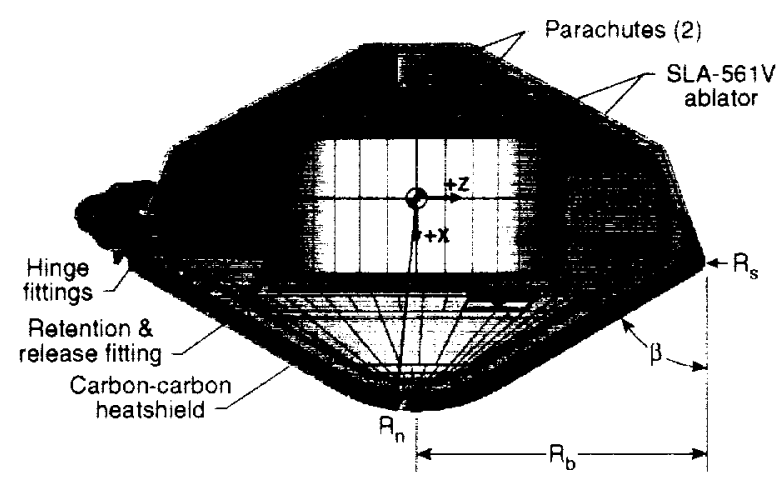

Figure 2. SRC layout.

Table 1. Parameters for SRC Geometry.

\begin{tabular}{ccc}
\hline Parameter & Baseline & Updated \\
\hline$\beta[$ deg $]$ & 59.81 & 59.81 \\
$\mathbf{R}_{\mathrm{n}}[\mathrm{m}]$ & 0.4394 & 0.4298 \\
$\mathbf{R}_{\mathrm{h}}[\mathrm{m}]$ & 0.7448 & 0.7543 \\
$\mathbf{R}_{\mathrm{s}}[\mathrm{m}]$ & 0.0332 & 0.0335 \\
\hline
\end{tabular}

dust $^{1-5}$ SRC. As with Stardust, NASA Langley Research Center (LaRC) has provided support to LockheedMartin Astronautics in their design of the Genesis SRC through entry aerodynamic. aerothermodynamic, and flight dynamics ${ }^{6-8}$ analyses of the capsule. This paper provides an overview of the aerothermodynamics effort.

The design of the Genesis spacecraft requires that the SRC be attached to the rest of the vehicle via three structural inserts of non-TPS material which pass through holes in the forebody heat shield. In this way, the collectors can be deployed from the aft side of the SRC. Figure 3 shows the size and locations of these heat shield penetrations. When the SRC separates from the spacecraft bus, the bolts are severed and retracted to

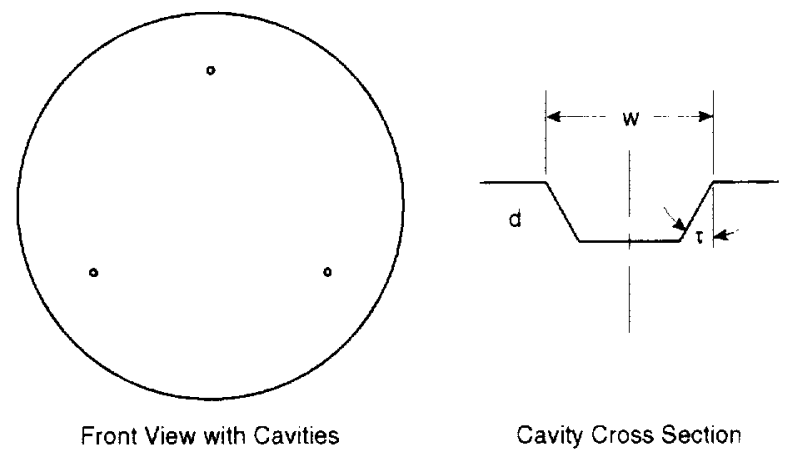

Figure 3. Penetration geometry on the forebody of the SRC flight article. 
form the cavities. The presence of these cavities during reentry may result in high. localized heating at the downstream edge of the cavities due to flow separation and reattachment within the cavities. accompanied by a heating augmentation downstream of the cavities. These penetrations could also induce transition to turbulence. which in turn could dramatically increase the heating environment aft of the penetrations.

Wind tunnels tests for the Apollo Command Module $^{\prime}$ and the Viking ${ }^{1 / 4}$ aeroshell show large increases in heating (greater than three times stagnation levels) immediately downstream of penetrations. Further downstream, heating levels were observed to be consistent with the onset of transition to turbulent flow. It could also be seen that the downstream heating levels are a function of cavity size.

The above results are not directly applicable to the Genesis SRC (due to differences in capsule geometry, cavity geometry, etc.), so computational fluid dynamics (CFD) calculations and wind tunnel phosphor thermography tests were employed. Since the cavities are very small at the scale of a wind tunnel model. quantification of the magnitude of the heat pulse within, and in the immediate vicinity of, the cavities was handled computationally. Wind tunnel tests using the phosphor thermography technique were used to determine the heating augmentation aft of the penetrations for a matrix of freestream conditions and cavity geometries. Finally, these experimental results were extrapolated to flight conditions using CFD. These results were a factor in the decision by Lockheed-Martin Astronautics to switch from the baseline PICA (Phenolic Impregnated Carbon Ablator) heat shield material to carbon-carbon.

\section{ANALYSIS}

\section{Numerical Approach}

Laminar, non-blowing. thin-layer Navier-Stokes solutions are generated with the Langley Aerothermodynamic Lpwind Relaxation Algorithm (LAURA)." LAURA is a finite volume. shock capturing algorithm capable of calculating flows in chemical and thermal nonequilibrium. It can be used for inviscid, thin-layer Navier-Stokes, or full Navier-Stokes computations. The solutions presented herein are for the thin-layer NavierStokes equations, except for one full Navier-Stokes solution in the sensitivity study. Turbulence calculations are performed using the Baldwin-Lomax ${ }^{12}$ algebraic model
For the flight cases, the flow was assumed to be in chemical (11-species air model) and thermal (separate translational and vibrational temperatures) nonequilibrium. For the surface catalysis. mass fractions were set to their values at the freestream temperature, resulting in a conservative estimate of the heating rate. Binary diffusion fluxes were corrected so that their sum equals zero. For the flight cases, one of two approaches was used: 1) $\mathrm{T}_{\mathrm{w}}=2900 \mathrm{~K}$ is specified. or 2) surface wall temperatures were computed using the radiative equilibrium wall temperature assumption with an assumed emissivity of 0.9

For the wind tunnel cases, the flow was treated as a perfect gas. A constant wall temperature of $\mathrm{T}_{w}=300 \mathrm{~K}$ was specified.

The numerical results presented herein were computed on SGI machines (32-bit word length). A single case was repeated on a Cray machine (64-bit word length) to verify that results are consistent. In all cases. solutions were judged to be converged when the surface heating values at selected points over the vehicle changed less than 0.01 per cent over 1000 iterations. Typically, 20.000 iterations were required to reach convergence.

\section{Experimental Method}

\section{0-Inch Mach 6 Tunnel}

With its high freestream Reynolds number range (1.6 to $29.5 \times 10^{6} \mathrm{~m}^{-1}$ ), the LaRC 20 -Inch Mach 6 facility is well suited for looking at transitional and turbulent flows. The tunnel has a two-dimensional contoured nozzle, with the bottom and top walls being contoured and the sidewalls parallel. The two-dimensional nozzle provides very uniform flow at the test section. Tempered glass windows on the top and two sides allow for a significant amount of visual access for the phosphor systems. Models are mounted on an injection system in a housing below the test section. During a run, the models can be injected in as little as $0.5 \mathrm{~s}$ (out of a total tunnel run time of $4 s$.

\section{Phosphor Thermography Technique}

The two-color phosphor thermography technique. as developed at NASA I .aRC. . $^{3}$ was used to obtain surface heat transfer data in the wind tunnel. With this method. ceramic wind tunnel models are coated with phosphor crystals, which fluoresce (when illuminated with ultraviolet light) with an intensity that is temperature dependent. 
During a wind tunnel run, intensity images are obtained with a state-of-the-art image acquisition system. Afterwards, the resulting intensity images are converted to quantitative temperature mappings using a weighted two-color relative-intensity fluorescence theory. Temperature data can be acquired even on wind tunnel models with complex geometries.

Once quantitative temperature mappings have been obtained, the next step is to derive heat transfer mappings. Given surface temperature variations over time at a location on a model, the heat transfer rate at that location can be inferred from one-dimensional heat conduction equations. Global heat transfer data can be efficiently obtained within minutes of a wind tunnel run. The LaRC phosphor thermography methods allows a three-orders-of-magnitude increase in the amount of heat transfer data gleaned from a given wind tunnel run, with an order-of-magnitude reduction in cost and time, as compared to conventional discrete gauge methods. This allows aeroheating information to be brought forward earlier in the design process than was previously possible.

The initial temperature and run temperature are the dominant uncertainties when lower surface temperatures are measured. Indeed, as the surface temperature approaches the initial temperature, the uncertainty climbs to infinity. The high precision errors in temperature are responsible for the large amount of scatter observed in phosphor heating data obtained from lower surface temperature readings. In most cases, though, the wall temperature measurements are higher, and in the case of the bias and total uncertainties, the uncertainty due to thermal properties is the most significant error source. For the majority of the temperature range, the resulting bias, precision, and total uncertainties are 7-8 per cent, 3-8 per cent, and 8-10 per cent, respectively

\section{Model Description}

Four different scale $(5,6.67,8.33$ and 10 per cent $)$ configurations were fabricated. The resultant model maximum diameters are $3,4,5$, and 6 in $(0.0752$, $0.1006,0.1392$, and $0.1504 \mathrm{~m}$ ), respectively. Four patterns, one of each desired model scale, were created using the stereo-lithography process. Using these patterns, models were cast with a fused silica ceramic investment casting method and coated with phosphor crystals. Eight models were fabricated, two of each model scale. The designations are as follows: the 3-in models are $3 \mathrm{~A}$ and $3 \mathrm{~B}$, the 4 -in models are $4 \mathrm{~A} / 4 \mathrm{~B}$, the 5 -in models are $5 \mathrm{~A} / 5 \mathrm{~B}$, and the 6 -in models are $6 \mathrm{~A} / 6 \mathrm{~B}$
Each model was manufactured with six cavities (of different sizes, radial positions, and depths) on the forebody. The cavity specifications are listed in Table 2 and shown in Figure 4. Cavity angular locations $(\theta)$ start from the left of the figure and proceed in a clockwise manner at 60-deg intervals. The cavities were placed at two different radial locations: 40 and 70 per cent of the maximum radius $\left(R_{b}\right)$ of the configuration. Three different cavity widths (nominally $0.5,1.0$. and 2.0 in at full scale) are included at the appropriate scaling. Nominal cavity depths are $0.03 \mathrm{in}$, with the exception of the cavity at $\theta=300 \mathrm{eg}$ which has a depth of $0.06 \mathrm{in}$.

Table 2. Cavity specifications for $1 / 10$-scale model.

\begin{tabular}{cccc}
\hline $\begin{array}{c}\text { Angular } \\
\text { location } \\
(\theta)[\text { deg }]\end{array}$ & $\begin{array}{c}\text { Radial } \\
\text { location } \\
\left(\mathrm{x} / \mathrm{R}_{\mathrm{h}}\right)\end{array}$ & $\mathrm{w}[$ in $]$ & $\mathrm{d}[$ in $]$ \\
\hline 0 & 0.70 & 0.10 & 0.03 \\
60 & 0.40 & 0.20 & 0.03 \\
120 & 0.40 & 0.10 & 0.03 \\
180 & 0.70 & 0.05 & 0.03 \\
240 & 0.70 & 0.20 & 0.03 \\
300 & 0.70 & 0.10 & 0.06 \\
\hline
\end{tabular}

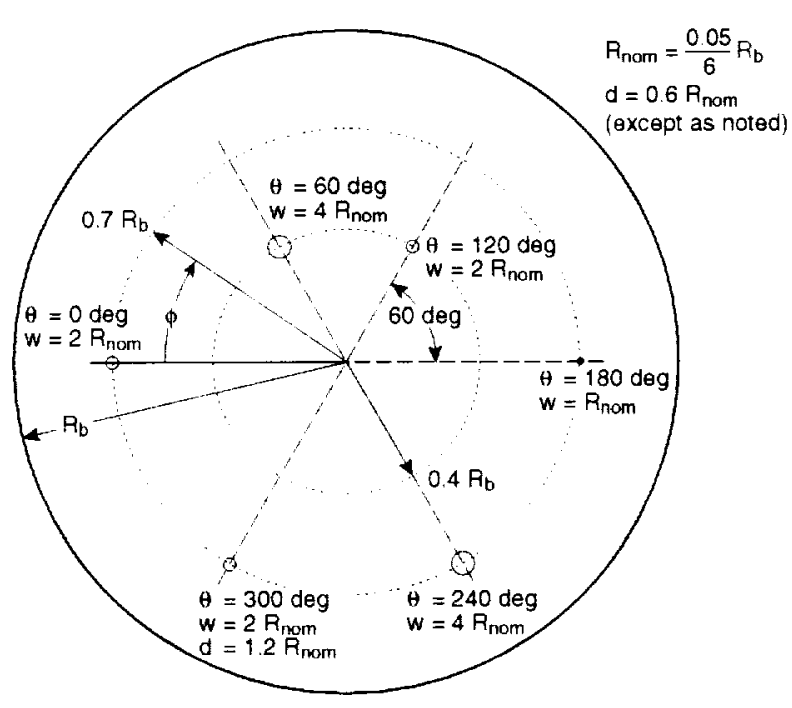

Figure 4. Schematic diagram of the cavity configuration for the wind tunnel models.

The cavity axis is normal to the surface. The wall of each cavity is canted at $\tau=35 \mathrm{deg}$ away from that axis (see Figure 2). In some cases (cavity at $\theta=300 \mathrm{deg}$ on model $4 \mathrm{~B}$, cavity at $\theta=0 \mathrm{deg}$ on $6 \mathrm{~B}$ ), the cavity (as cast) was not satisfactory on the final model. The cavity was restored at these locations by drilling a hole normal 
to the surface to the desired depth. This approach does not preserve the 35-deg taper for these cavities, however.

\section{RESULTS AND DISCUSSION}

\section{Computational Trajectory Focal Points}

Initially, solutions over the forebody were calculated for three points $(t=260.270,280 \mathrm{~s})$ along the nominal trajectory. The stagnation point heat pulse (evaluated using the Fay-Riddell relation) and freestream Re history from that trajectory are shown in Figure 5, along with all trajectory points at which NASA LaRC performed calculations. Freestream conditions for those points are given in Table 3.

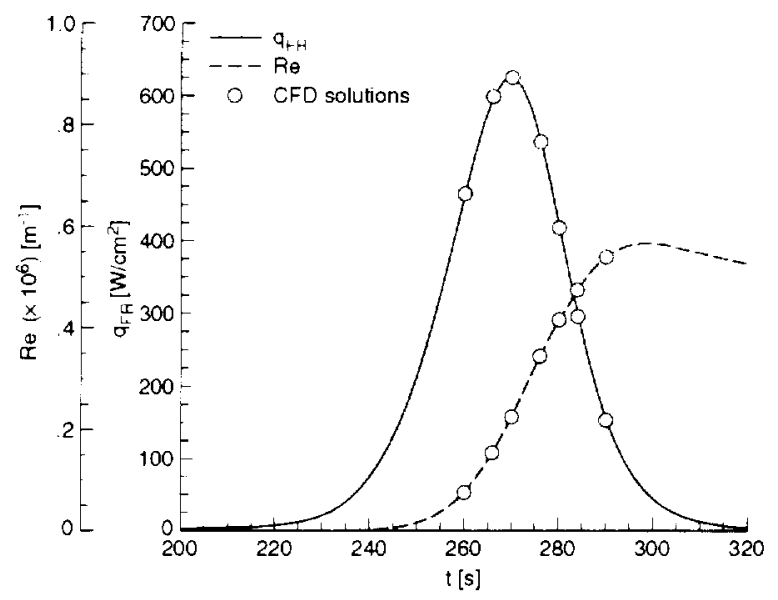

Figure 5. Reference heating and Reynolds number history from nominal trajectory.

\section{Computational Sensitivity Study}

The effect of grid resolution and thin-layer NavierStokes assumption on the laminar, non-blowing, surface heating for the smooth forebody of the Genesis Sample Return Capsule (SRC) was examined. LAURA solutions were generated at the peak heating point of a nominal trajectory with grids of varying resolution in
Table 3. Freestream Conditions at Calculation Points Along Nominal Trajectory

\begin{tabular}{|c|c|c|c|c|c|}
\hline$t \mid s]$ & $V|m / s|$ & $\rho\left[\mathrm{kg} / \mathrm{m}^{+}\right]$ & $\mathrm{T} \backslash K \mid$ & $R e\left[100^{\prime} m^{\prime}\right]$ & Note \\
\hline 260 & 104911 & $1.12 .3 c^{2}-4$ & 216.8 & 0.11755 & \\
\hline 266 & 4955 & $2.3532-4$ & 2344 & 0.11180 & \\
\hline 270 & 9360 & $3.781 \mathrm{e}-1$ & 244.6 & 0.2254 & Peak heating \\
\hline 276 & 8098 & $6.920 \mathrm{c}-4$ & 255.7 & 0.2410 & \\
\hline 280 & 7092 & $9.728 \mathrm{c}-4$ & 262.1 & 0.4156 & Peak pressure \\
\hline 284 & 6059 & $1.312 \mathrm{e}-3$ & 264.6 & 0.3325 & \\
\hline 2901 & 4625 & $1.932 \mathrm{c}-3$ & 261.4 & 0.3775 & \\
\hline
\end{tabular}

both the streamwise and normal directions. Freestream conditions at the peak heating point along the trajectory (see Table 3 ) were used for all computational solutions. To simplify the calculations, a constant wall temperature of $2900 \mathrm{~K}$ was assumed. This value falls within the range of calculated radiative equilibrium surface temperatures.

A grid of 100 streamwise by 64 body-normal cells over the baseline SRC forebody was generated for preliminary aerothermodynamic computations. The grid contains 30 cells in the streamwise direction on the spherical nose cap. 40 cells on the conical flank. and 30 cells on the rounded shoulder. This grid served as the baseline grid for all computations over the smooth forebody.

In order to assess the effects of grid density and clustering on the forebody surface heating, a number of laminar solutions were computed over grids derived from the baseline grid. The streamwise grid density was varied by coarsening the baseline grid in each region independently. The grid clustering in the normal direction was altered by varying the cell Reynolds number $\left(\operatorname{Re}_{i e \text { ell }}\right)$ based on the local speed of sound for the first cell away from the wall. The number of cells in the normal direction was also varied. Table 4 lists the matrix of grids.

Table 4. Grid Resolution Run Matrix

\begin{tabular}{c|rcc|cc|c}
\hline \multirow{2}{*}{ Grid } & \multicolumn{3}{|c|}{ Streamwise Cells } & \multicolumn{2}{|c|}{ Normal Direction } & \multirow{2}{*}{ Note } \\
\cline { 2 - 6 } & Nose & Cone & Shoulder & Cells & Re $_{\text {vell }}$ & Current L.AURA default \\
\hline 0 & 15 & 20 & 15 & 64 & 10 & Nettelhorst and Mitcheltree $^{1+}$ \\
1 & 15 & 20 & 15 & 64 & 2 & Fine grid (normal) \\
2 & 15 & 20 & 15 & 128 & 1 & Extra-coarse nose. coarse shoulder \\
3 & 6 & 20 & 10 & 64 & 10 & Fine grid (streamwise) \\
4 & 30 & 40 & 30 & 64 & 10 & Coarse nose. coarse shoulder \\
5 & 10 & 20 & 10 & 64 & 10 & \multicolumn{2}{c}{} \\
\hline
\end{tabular}




\section{Effect of Normal Grid Clustering}

Three grids were used to estimate the effect of grid clustering in the normal direction on surface heating. Referring to Table 4, these are the low wall-resolution default grid with $\operatorname{Re}_{\text {cell }}=10$ (Grid 0 ), a medium wallresolution grid recommended by Nettelhorst and Mitcheltree ${ }^{14}$ (Grid 1 ) with $\operatorname{Re}_{c i t}=2$, and a fine resolution grid with 128 cells in the body-normal direction and $\mathrm{Re}_{\mathrm{ce} \|}=1$ (Grid 2$)$. The surface heating computed over these grids is shown in Figure 6.

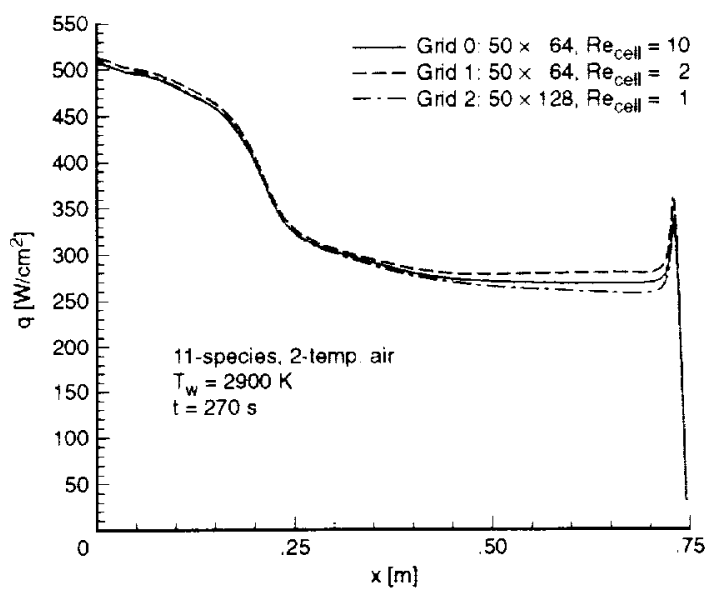

Figure 6. Effect of normal grid clustering on surface heating.

Results from all three grids show similar heating levels in the stagnation region with variations at the stagnation point of 1 per cent. The primary effect of the grid clustering occurs on the conical flank and on the shoulder. Using the fine resolution grid (Grid 2) as the baseline, the medium resolution grid (Grid 1) predicts heating levels that are 9 per cent higher at the end of the cone and on the rounded shoulder. The low-resolution grid (Grid 0 ) does a better job by predicting heating levels that are within 4 and 1 per cent of the baseline levels on the cone and shoulder, respectively. The observation that the grid with a lower resolution at the wall $\left(\operatorname{Re}_{\text {cell }}=10\right)$ gives heating rates closer to highest resolution $\left(\mathrm{Re}_{\mathrm{u} \text { ill }}=1\right)$ ) than the grid with the medium resolution $\left(\operatorname{Re}_{\mathrm{e} e l l}=2\right)$ appears to be counterintuitive. However. for a given number of normal cells, reducing the resolution at the wall decreases the amount of grid stretching and gives a better distribution of grid points across the entire boundary layer. Based on this comparison, 64 cells in the normal direction with $\mathrm{Re}_{\mathrm{er}\|\|}=10$ adequately resolves the laminar heating and will be used for the remaining solutions

\section{Effect of Streamwise Grid Density}

Four grids with varying numbers of streamwise cells were used to estimate the effect of streamwise grid density on surface heating. In the nose region, solutions were computed using grids with $30,15,10$ and 6 cells (corresponding to Grids $4,0,5$, and 3 in Table 4 , respectively). Figure 7 depicts the heating levels in the nose region for each grid. The heating levels using all four grids are very similar with only the 6-cell run showing a relatively small deviation of 4 per cent at the stagnation point. Since the 10 nose-cell solution is on par with the higher resolution results, and the reduction in total computational time is minimal for the 6 nosecell grid over the 10 nose-cell grid, 10 cells in the nose region will be used for the remainder of this study.

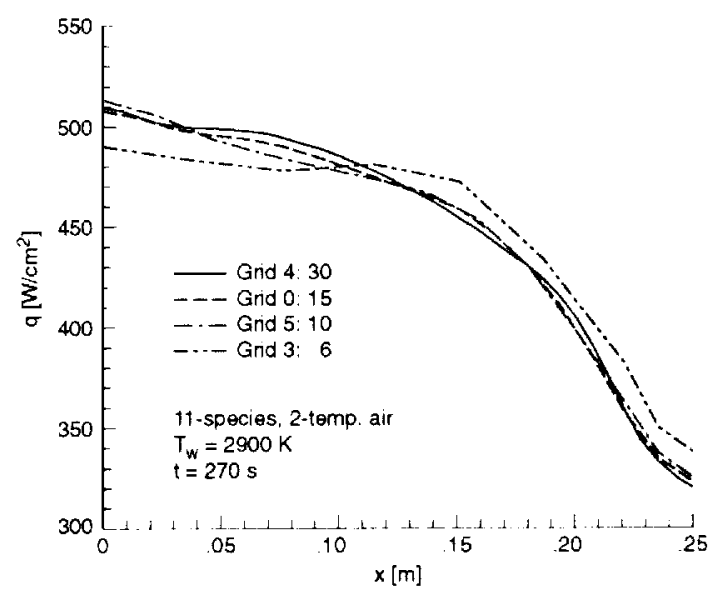

Figure 7. Effect of streamwise grid density on nose heating.

The effect of the number of streamwise cells on the heating levels in the shoulder region is shown in Figure 8 . Solutions are computed using grids with 30,15 , and 10 cells in the shoulder region (corresponding to Grids 4, 0, and 5 in Table 4, respectively). The peak heating rate on the shoulder predicted by the three grids agree to within 3 per cent and occurs at the end of the conical flank and beginning of the shoulder region. This comparison suggests 10 cells in the shoulder region are sufficient to resolve the area around the cone-shoulder interface where the local peak in heating occurs, and that resolution will be used for this study.

Results for Grids 4 and 0 (with 40 and 20 cells on the cone, respectively) have heating rates along the cone within 1 per cent of each other (not shown). Although an even coarser grid on the flank might adequately predict heating levels, 20 cells will be used in 
anticipation of including cavities on the forebody in future computations.

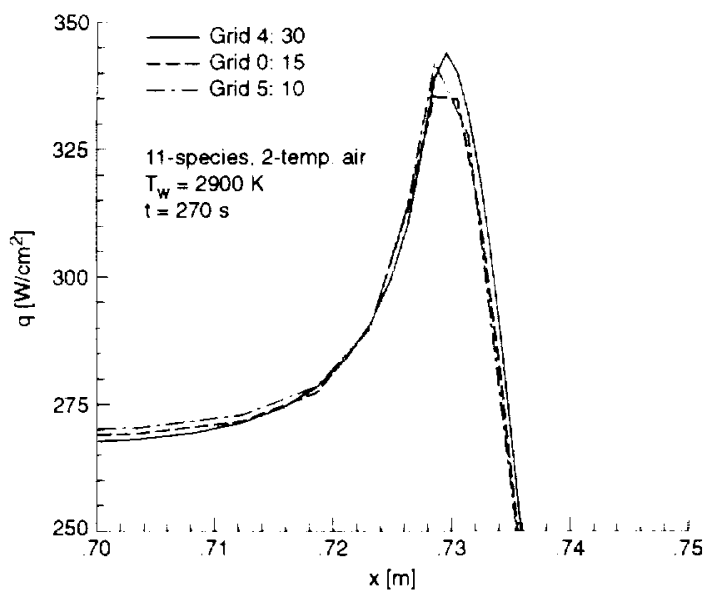

Figure 8. Effect of streamwise grid density on shoulder heating.

\section{Effect of Navier-Stokes Equation Set}

Although not shown, the thin-layer Navier-Stokes solution on Grid 0 was repeated using the complete Navier-Stokes equation set. There is no discernible difference between the two solutions, suggesting that the use of the thin-layer Navier-Stokes equations is appropriate for computations over the forebody.

\section{Laminar Heating Calculations}

\section{Smooth Forebody (No Cavities)}

Laminar surface heating rates over the smooth forebody of the baseline SRC were calculated for three points $(t=260.270,280 \mathrm{~s})$ along a nominal trajectory. With the sensitivity study as a guide, each solution used a grid with 40 cells in the streamwise direction (10 on the nose. 20 on the conical flank, and 10 on the rounded shoulder) and 64 cells normal to the body. The grid was clustered in the normal direction using a cell Reynolds number of 10 . A radiative equilibrium wall temperature was prescribed. The surface heating and temperature distributions for these cases, which exhibit the expected levels as the vehicle traverses the heat pulse, are shown in Figure 9. The distribution at peak heating will serve as a reference for later calculations that include the effects of the cavity, as well as turbulence.

\section{Axisymmetric Solutions With Cavity}

The impact of the cavity was first addressed by modifying the baseline grid to include a dimple. Note

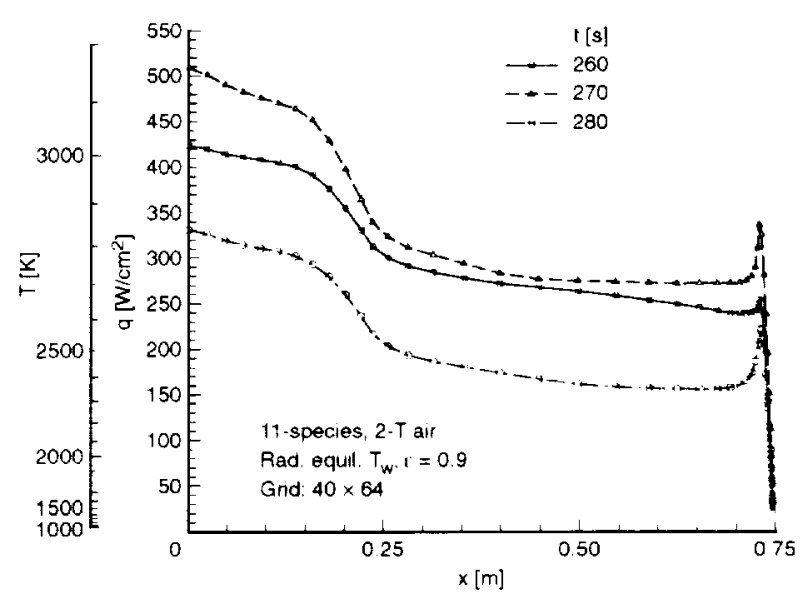

Figure 9. Surface heating and temperature distributions for points along nominal trajectory.

that this actually models the $3-\mathrm{D}$ cavity as an axisymmetric "groove". A cavity with dimensions $0.75 \times 0.3$ in $(w=1.905 \mathrm{~cm} . \mathrm{d}=0.762 \mathrm{~cm})$ and taper of $\tau=45 \mathrm{de} g$ was modeled. The conical portion of the baseline grid from the earlier sensitivity study was modified to include the feature. The resultant grid again has 10 cells on the nose and 10 cells on the shoulder. There are 1.3 cells between the nose and dimple, 12 cells within the dimple (uniformly-spaced). and 16 cells between the dimple and shoulder, yielding a grid of dimensions $61 \times$ 64 cells.

Axisymmetric calculations were performed for the freestream conditions at peak heating (see Table 3 for $\mathrm{t}=270 \mathrm{~s})$. A constant wall temperature of $2900 \mathrm{~K}$, which falls within the range of radiative equilibrium surface temperatures seen in Figure 9, was prescribed. Results in Figure 10 show a spike on the downstream lip of the cavity whose magnitude is more than three times the stagnation value of $510 \mathrm{~W} / \mathrm{cm}^{2}$ (see Figure 9). The smooth forebody solution is included for reference. The surface with the cavity geometry is shown in gray the freestream velocity vector points down and the downstream lip is on the right).

A grid sensitivity study was conducted for the cavity, and those results are also presented in Figure 10. First. the grid density within the dimple was doubled to 24 cells. and the resolution between the cavity and the shoulder increased to 31 cells, yielding a grid with dimensions $88 \times 64$. A third case increased the dimple refinement to 48 cells, and the downstream refinement to 43 cells, yielding a $124 \times 64$ grid. The results show that the two highest grid densities give similar results for the flow separation at the upstream lip. However. both the breadth and magnitude of the pulse is strongly 


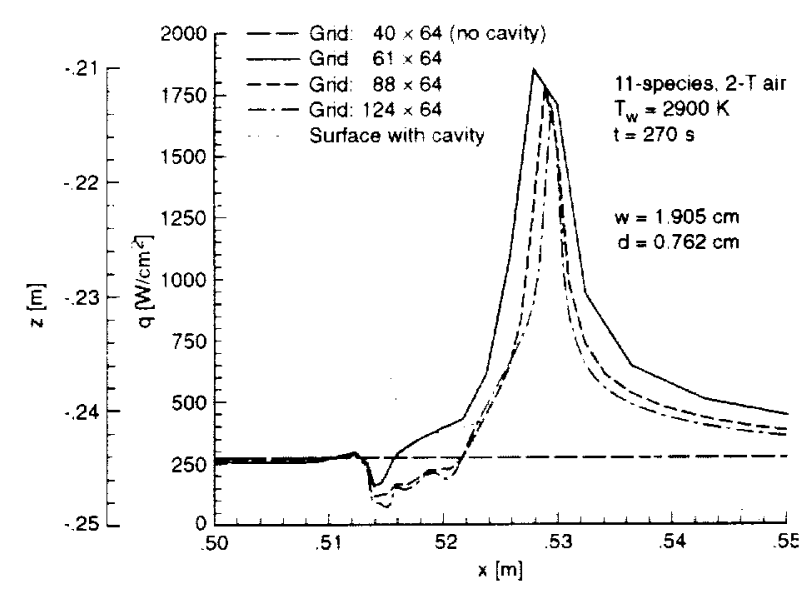

Figure 10. Effect of grid resolution and geometry on heating in vicinity of cavity.

dependent on the resolution provided by the grid. Still, the heating levels of the spike for the 88- and 124-cell grids differ by less than 4 per cent.

With the maturation of the SRC design, a switch was made to a cavity with dimensions $1.0 \times 0.3$ in ( $w=2.540 \mathrm{~cm} . \mathrm{d}=0.762 \mathrm{~cm}$ ) and taper of $\tau=35 \mathrm{deg}$. The $88 \times 64$ grid from Figure 10 was modified to match the new geometry while maintaining the streamwise spacing near the lip. Outside the cavity, the surface grid is virtually identical to the $88 \times 64$ grid. The result is a grid with dimensions $89 \times 64$. Figure 11 shows the impact of that switch on the heating augmentation. Note that the primary change (an increase in the magnitude of the pulse relative to the $88 \times 64$ grid) appears to be due to taper angle of the cavity wall relative to the forebody inclination.

A grid independent solution of heating around a sharp corner is virtually unattainable, and in reality any corner will have a finite radius. Therefore, the effect of corner rounding is examined next. First. a radius of $\mathbf{R}_{\mathrm{c}}=0.33 \mathrm{~cm}$ was added to the downstream lip of the cavity for the $89 \times 64$ grid. The new grid has 34 cells within the dimple and 34 cells between the dimple and the shoulder, yielding a grid with 100 streamwise cells. A comparison of those two solutions in Figure 11 shows that rounding the cavity corner significantly reduces the heating spike. Still, even with rounding, the strength of the spike on the downstream lip of the cavity is on the order of 2-3 times the stagnation value. The grid sensitivity is shown by coarsening the mesh around this corner by a factor of two to produce a $94 \times 64$ grid. The magnitude of the resultant heat spike is 6 per cent less than that of the finer grid.

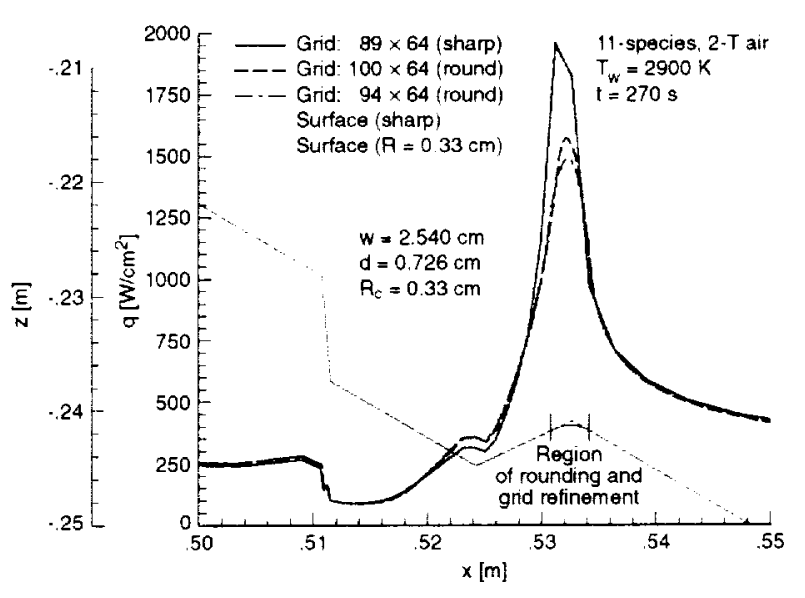

Figure 11. Effect of edge radius and grid resolution on heating in vicinity of cavity.

The next step is to add a rounded corner to the upstream lip. A new grid was generated over the updated geometry (see Table 1) using 10 cells on the nose and 10 cells on the shoulder. It has 16 cells before the dimple. 46 cells within the cavity ( 6 on the upstream radius, 8 on the upstream edge, 12 along the bottom, 8 on the downstream edge, and 12 on the downstream radius), and 24 cells downstream of it, yielding a grid of dimensions $106 \times 64$ cells. A coarsened version of this grid omits every other node within the cavity (dropping it to 23 cells) to produce a grid of $83 \times 64$ cells.

Solutions were calculated over these grids at the $\mathrm{t}=270 \mathrm{~s}$ flight conditions. A radiative equilibrium wall temperature boundary condition was used. The results are shown in Figure 12. Note that the rounding of the upstream lip has less effect on the heating levels than

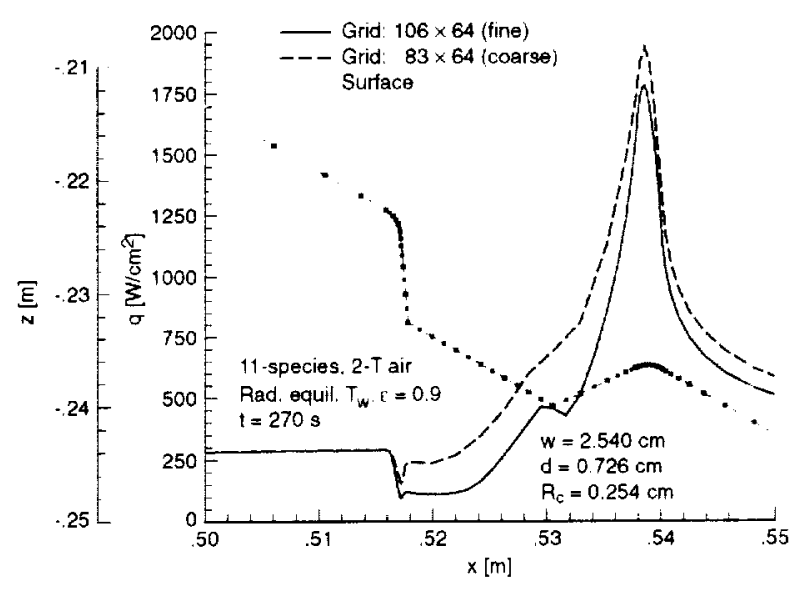

Figure 12. Effect of streamwise grid resolution on heating in vicinity of rounded cavity. 
rounding the downstream lip. As one might expect, the coarsening of the grid tends to smear the features within the cavity, while the peak value changes by 10 per cent

\section{3-D Solutions With Cavity}

The above axisymmetric solutions were used in the preliminary analysis of the candidate cavity geometries. A limited number of solutions were computed for a true three-dimensional cavity of dimensions $1.0 \times 0.3$ in $(w=2.540 \mathrm{~cm}, \mathrm{~d}=0.762 \mathrm{~cm})$, with $\mathrm{R}_{\mathrm{c}}=0.33 \mathrm{~cm}$ and taper of $\tau=35 \mathrm{deg}$. In preparation for these solutions. a singularity-free grid was generated for the updated forebody shape (see Table 1) with a cavity staggering the symmetry plane. (The singularity-free topology has no pole boundaries and thus avoids the associated computational convergence problems.)

A solution at wind tunnel conditions was computed over the singularity-free grid of dimensions $146 \times 64$ $\times 64$. For comparison, an axisymmetric solution using the $100 \times 64$ cell grid from above was computed at the same conditions. Although not shown, the symmetry plane solution from the singularity-free grid compares well with the axisymmetric solution at the nose. along the cone, and at the shoulders. As shown in Figure 13. heating in the symmetry plane for the three-dimensional penetration is 10 per cent less than axisymmetric dimple. apparently due to a relieving effect. Note that the disconnects in the 3-D solution correspond to the boundaries between the 16 computational blocks. The breaks are the result of post-processing (when the cell-

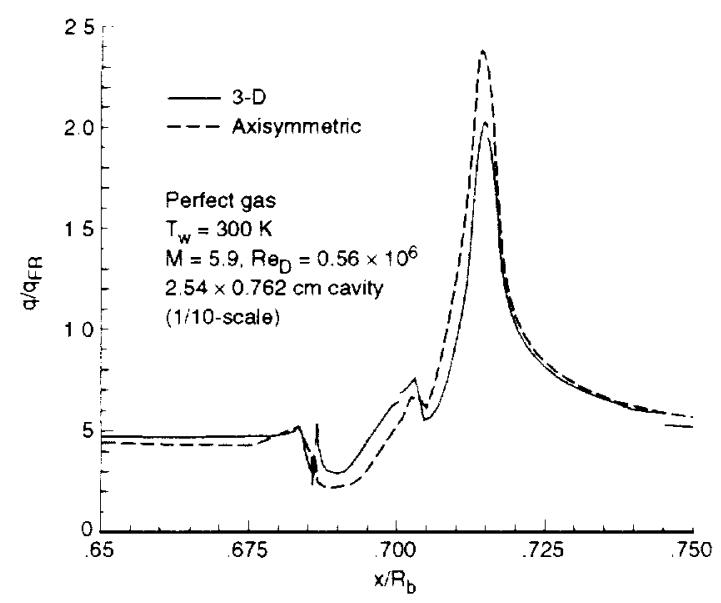

Figure 13. Laminar centerline heating computations in vicinity of cavity at wind tunnel conditions. centered results are extrapolated to the surface to produce face-centered values, which are then shifted to the corner nodes for plotting) and are not indicative of solution discontinuities.

Streamline patterns within the cavity are shown in Figure 14 for the wind tunnel case. The flow separates as it expands around the upstream lip and reattaches on the downstream wall. The streamlines are colored by local enthalpy, showing the high energy levels after flow reattachment. Contours of local heating for this case are shown on the left half of Figure 15 and reveal an important piece of information. For the threedimensional cavity, the heat pulse maximum is pushed off the centerline. That maximum is of the same order as the maximum value from the corresponding axisymmetric solution. Thus, contrary to the indications of Figure 13, the three-dimensional nature of the flow merely serves to shift the location of the heat pulse without significantly changing its intensity

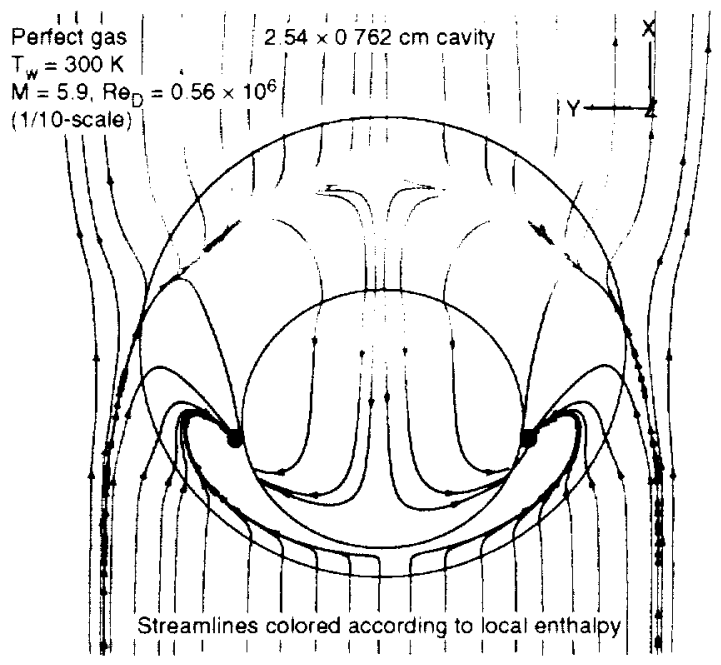

Figure 14. Front view of streamlines inside cavity at wind tunnel conditions.

The right side of Figure 15 shows the heating contours for the peak heating trajectory point. Note that the hot spot for flight conditions (maximum $q / \mathrm{q}_{\mathrm{l}: \mathrm{R}}=2.95$ ) is much stronger than wind tunnel conditions (maximum $q / q_{1 R}=2.33$ ), and it is located closer to symmetry plane. As a result of this intensity at flight conditions. the affect of the cavity is felt for a longer distance downstream than in the wind tunnel (as indicated by the contours at the top of Figure 15). 


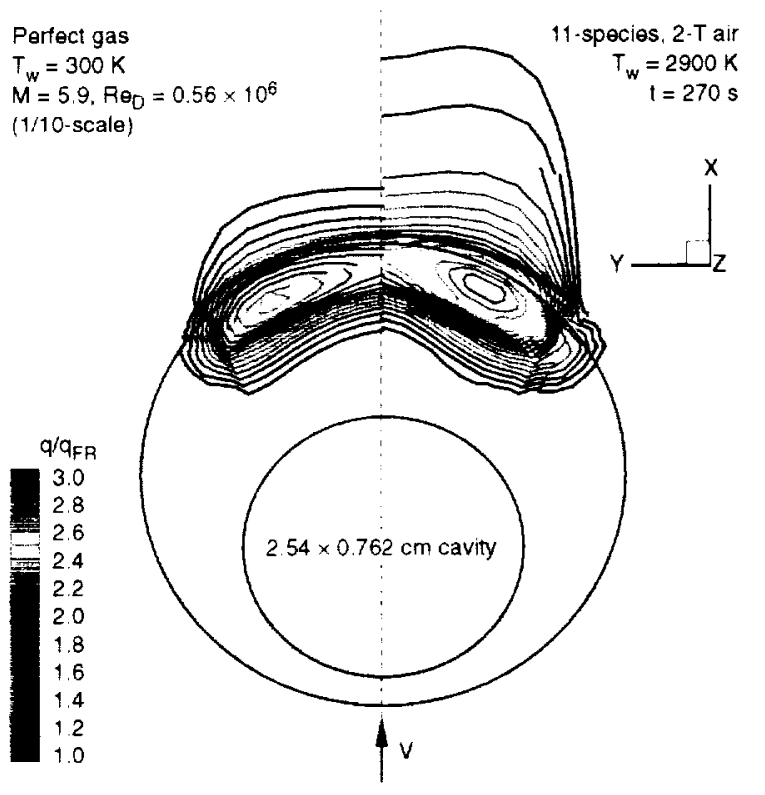

Figure 15. Front view of heating inside cavity at wind tunnel and night conditions.

\section{Wind Tunnel Results and Repeatability}

The primary objectives of the wind tunnel tests were to determine the effectiveness of a cavity as a boundary layer trip, to assess the dependence of this effectiveness on cavity geometry, to observe the region of downstream influence, and determine the level of downstream heating augmentation resulting from the interaction. A total of 29 wind tunnel runs were conducted at various Re and orientations. A sampling of the resultant phosphor thermography images is provided in Figure 16.

All three images in Figure 16 show augmented heating streaks due to the presence of the cavities. Figure $16 \mathrm{a}$ represents the highest $\mathrm{Re}$ tests $\left(\operatorname{Re}_{\mathrm{D}}\right)=$ $\left.3.81 \times 10^{6}\right)$. Heating levels 60 per cent higher than stagnation values are observed aft of the cavities. Figure $16 \mathrm{~b}$ is a close-up shot which shows that the heating on the downstream edge of the cavity spikes up (as seen in the computational results). In figure $16 \mathrm{c}$, the results are at $\alpha=15 \mathrm{deg}$. In this case, the heating aft of the cavity has a cusped shape as the flow follows the streamlines. (The Genesis SRC will nominally fly at $\alpha=0 \mathrm{deg}$, so the bulk of the results herein are for that orientation. Results at angle-of-attack are included in the transition map to be presented later. )

An assessment of experimental data integrity is presented in Figure 17. Figure 17a provides the temporal collapse of a sample run at $\operatorname{Re}_{\mathrm{p}}=1.10 \times 10^{6}$, and

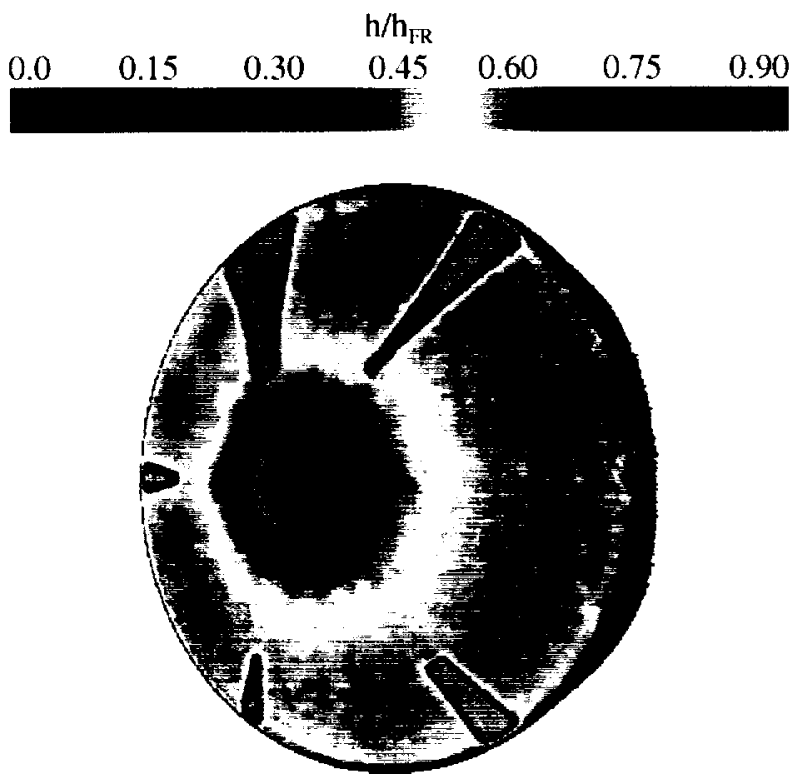

(a) Model 6A, $\alpha=0$ deg, $R e_{D}=3.81 \times 10^{6}$.

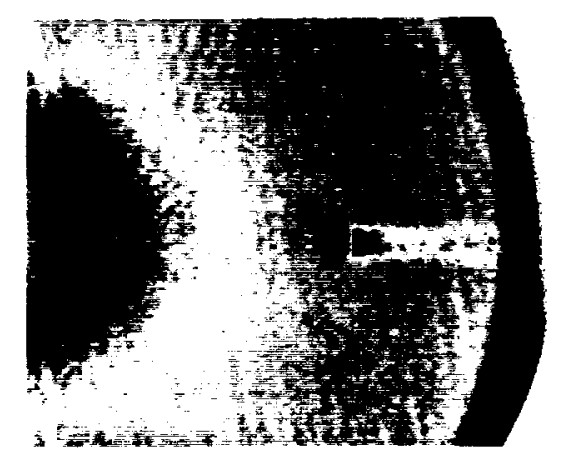

(b) Model 6A, $\alpha=0$ deg. $R e_{l}=1.11 \times 10^{h}$ (I-in cavit) .

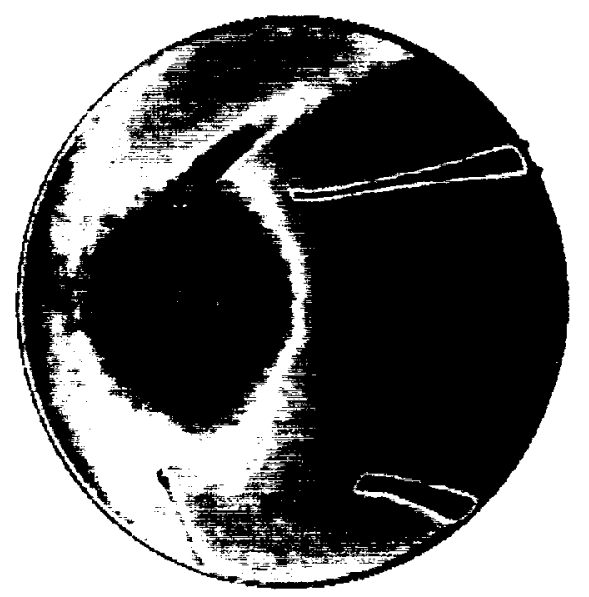

(c) Model $6 A, \alpha=15 \mathrm{deg}, \operatorname{Re}_{p}=1.56 \times 10^{\circ}$.

Figure 16. Sample phosphor thermography heat transfer images. 
shows that the heat transfer coefficient levels achieve steady-state values. Figure $17 \mathrm{~b}$ compares runs where the only variable is model size, with relatively good scalability. Although not shown. a repeat run with the same model as well as a run with an identical model show good (within 3 per cent variability) run-to-run and model-to-model repeatability, respectively.

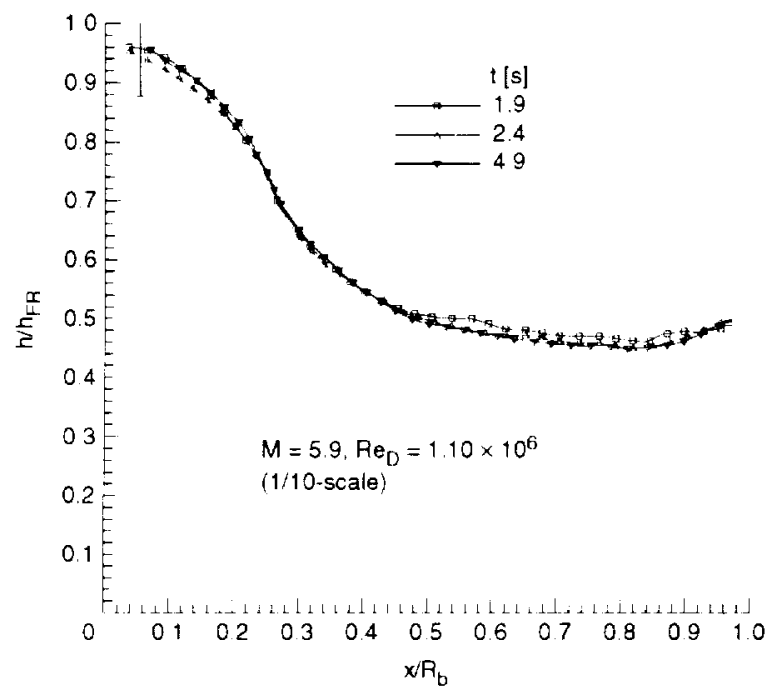

(a) Temporal collapse of data for sample run.

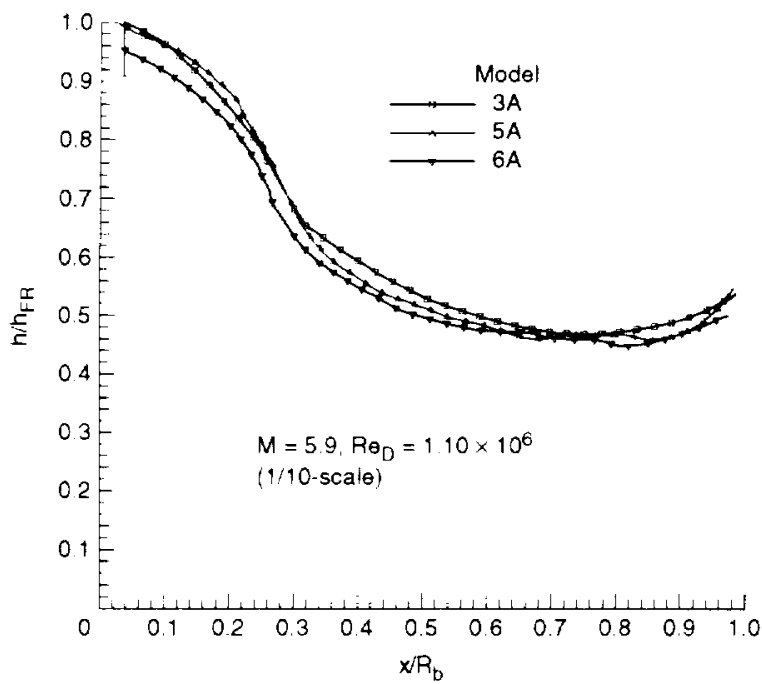

(b) Scalahility of different size models.

Figure 17. Data integrity test $(\alpha=0 \mathrm{deg})$.

\section{Observations from Experiment}

The cavities have two primary effects on the heating. First, as seen in the computational results. a large heat pulse is typically generated on the down-stream wall of the cavity. As can be seen in Figure 16b. the presence of this pulse can impact local heating downstream of the cavity. Second, if the flow is sufficiently energetic. the presence of the cavity can serve to trip the flow to turbulence (see Figures $16 a$ and $16 c$ ).

Figures 18 and 19 present line cuts of the thermophosphor data from the $\alpha=0$ deg runs. In Figure 18. each subfigure shows the heating for the six cavities at a given Re. The first observation is that the smallest cavity produces no discernable heat spike or tripping effect at any of the Re lested. Further, the flow returns to laminar levels downstream of all cavities at the lowest Re (Figure 18a). For the middle Re (Figure 18b). the downstream levels are consistent with a transitioning to turbulent flow. At the highest Re (Figure 18c), the flow appears to approach fully turbulent values downstream of all cavities (save the 0.5 -in hole). Thus, for a given Re. all but the smallest cavity are equally effective as tripping devices. A forward cavity position allows more running length for tripped flow to grow to fully turbulent values downstream. However, for the relatively short running length of this forebody, the location of the penetration appear's to have only a minor impact on the heating levels realized aft of the cavity. It should be noted that the variation toward the end of the body is probably due to the presence of the shoulder (and the associated flow expansion).

In Figure 19, each subfigure shows the heating variation with respect to Re for a given cavity. A subfigure for the smallest cavity is not included since its influence appears to be benign. Note that the subfigures for the nominal and 2-in cavities contain data from both radial locations. It is clear from these figures that a larger cavity produces the strongest heat pulse. For both the nominal and 2-in cavities, the location nearest the stagnation point experiences a stronger heat pulse than its downstream counterpart. A comparison of subfigures $19 \mathrm{a}$ and $19 \mathrm{~b}$ shows little difference between the 1 in cavities of depth 0.03 in and 0.06 in. respectively. Any differences could be due to the tidelity of the modeling of the cavities, rather than a dependence on cavity depth 


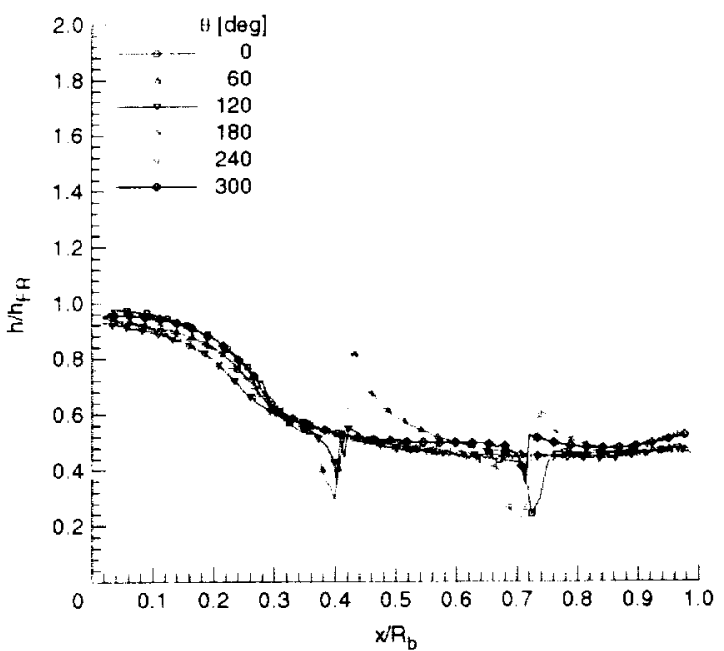

(a) $R_{D}=0.80 \times 10^{6}$

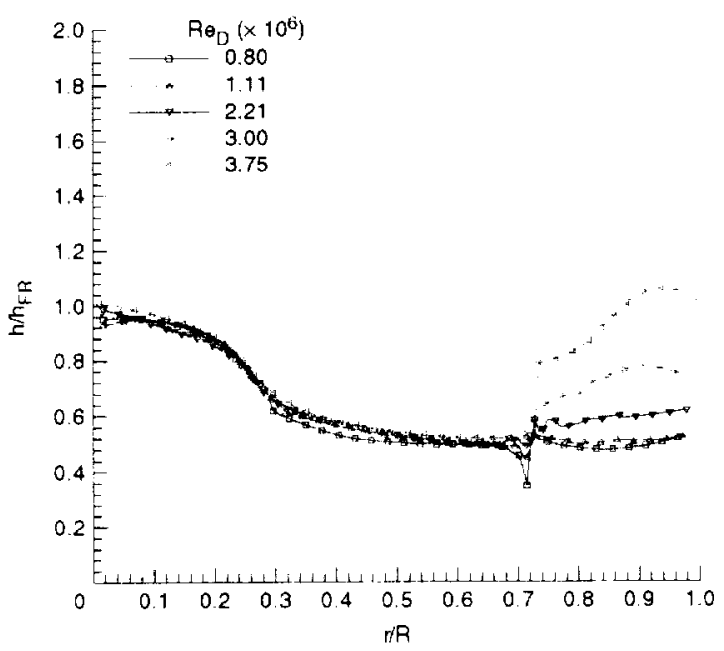

(b) $R e_{b}=2.21 \times 10^{\circ}$

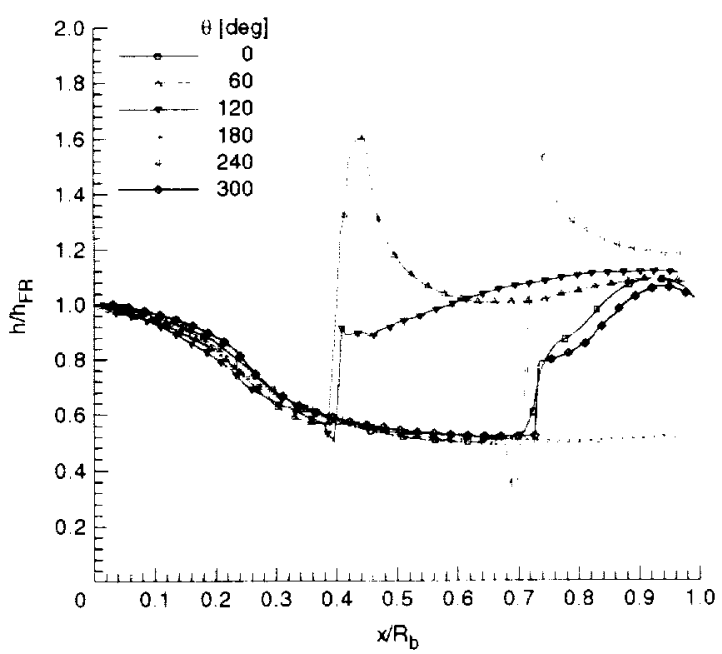

(c) $R e_{D}=3.75 \times 10^{\circ}$

Figure 18. Comparison of phosphor line cuts $(\alpha=\mathbf{0}$ deg $)$, sorted by $\mathbf{R e}_{\mathrm{T}}$.

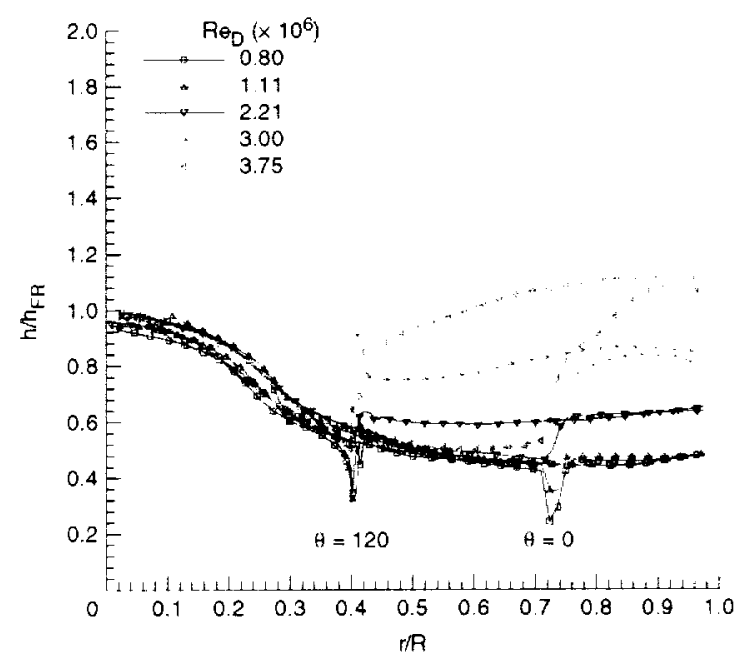

(a) Cavity size: $w=1$ in, $d=0.3$ in $(\theta=0,120$ deg $)$

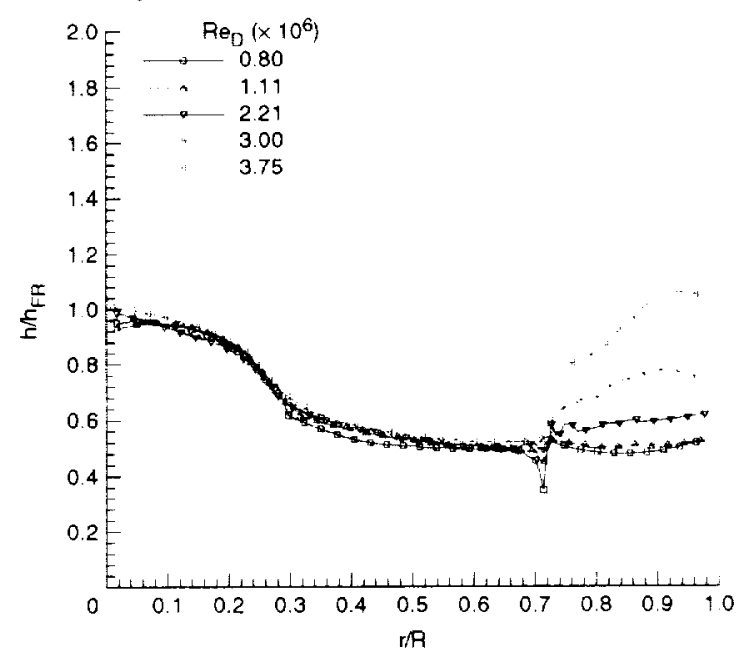

(b) Cavity size: $w=1$ in, $d=0.6$ in ( $\theta=300$ deg)

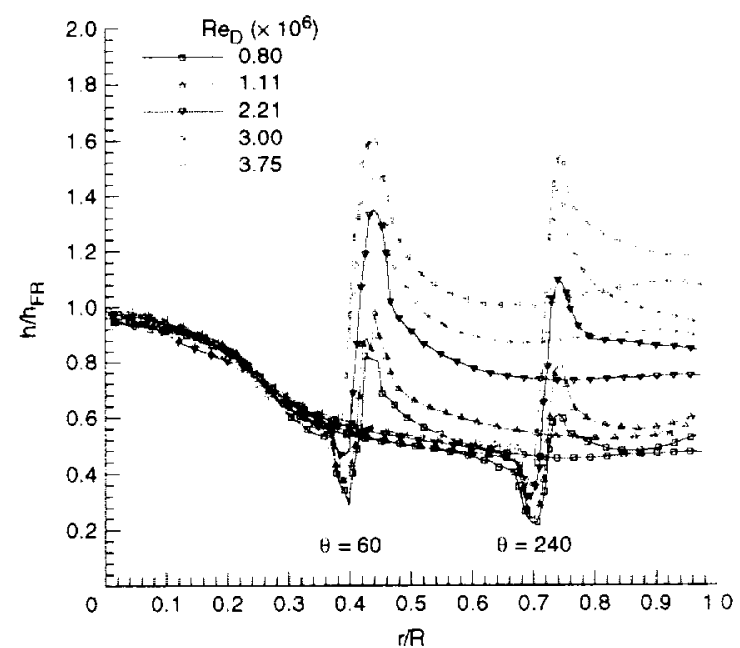

(c) Cavity size: $w=2$ in, $d=0.3$ in $(\theta=60,240$ deg)

Figure 19. Comparison of phosphor line cuts $(\alpha=0 \mathrm{deg})$, sorted by cavity size. 
Figure 20 provides a comparison between experimental results at $\left.\mathrm{Re}_{1}\right)=1.1 \times 10^{6}$ (where the flow appears to remain laminar downstream of the 0.5 -in cavity) and LAURA computations over a smooth forebody. Note the agreement is excellent overall. The largest differences are in the region of the shoulder. where the phosphor image resolution is insufficient to characterize the heating pulse associated with the small radius of curvature.

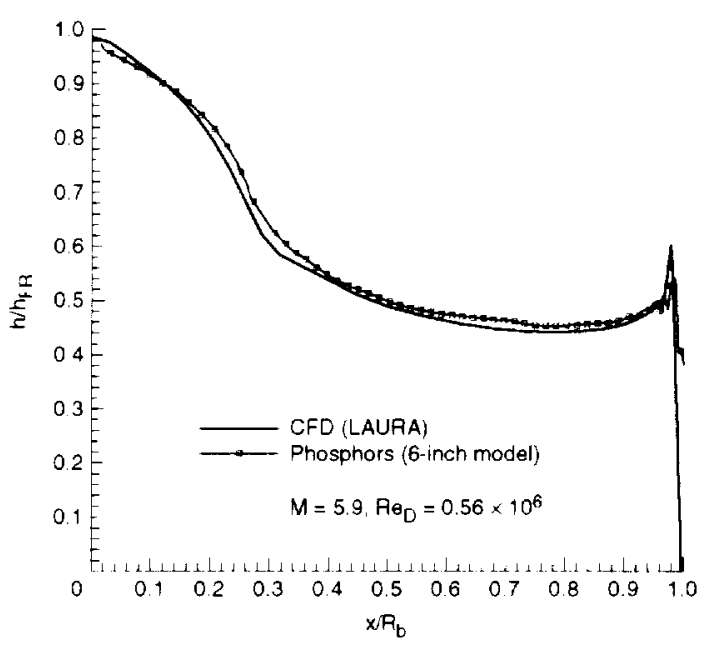

Figure 20. Comparison of phosphor line cuts with computational results $(\alpha=0 \mathrm{deg})$.

\section{Transition Map}

A transition map was developed as a means of extrapolating these wind tunnel data to flight. Computational results for the wind tunnel conditions were used to calculate boundary layer properties $(\Theta . \delta)$ for the wind tunnel conditions. These, in turn, were used to construct a plot of $\operatorname{Re}_{\Theta}$ versus $w / \delta$ for the experimental data set. Figure 21 shows the final product. The set of phosphor images were used to define which cavities and conditions produced incipient, transitional, or turbulent flow downstream. The symbols are colored (laminar, turbulent, etc.) according to those interpretations of the images.

The data was augmented with two power law curves to estimate the laminar and turbulent boundaries. Then a sketch of the flight trajectory (including the peak heating and peak dynamic pressure points) was overlayed on the figure. Based on the resultant map. the flow aft of the penetrations will still be laminar at the peak heating point of the nominal flight trajectory. As the vehicle continues along the trajectory toward the peak dynamic pressure point, a transition to turbulent flow aft of the penetrations is predicted fully turbulent flow could be realized at the peak dynamic pressure point.

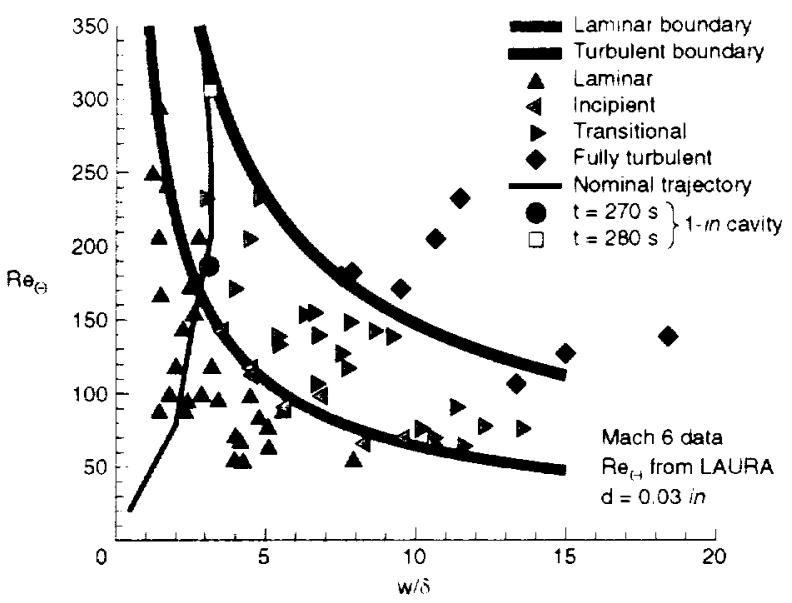

Figure 21. Transition map for forebody cavities.

Note that the numerical solutions show that, for wind tunnel conditions. $M$ is subsonic at all of the cavities, except on the leeside for runs at angle of attack. Flight conditions yield supersonic $\mathbf{M}_{r}$ at the cavity locations. As a result, using $\mathrm{Re}_{\theta}$ rather than $\mathrm{Re}_{\mathrm{H}} / \mathrm{M}_{c}$ to extrapolate results to flight should give a more conservative estimate for the heating environment. Additional areas of conservatism stem from the fact that wind tunnel noise typically trips a flow earlier than in free flight.

\section{Turbulent Heating Calculations}

The turbulent values were calculated using a Baldwin-Lomax algebraic turbulence model. ${ }^{12}$ For the smooth forebody calculations, a beginning point for transition to turbulence was specified at a radial location of $x=0.7 R_{b}$. The turbulent solutions were computed using 80 cells in the normal direction with $\operatorname{Re}_{\mathrm{w} i l l}=$ 2. This gives a better near-wall resolution in the turbulent region and increases the heating by approximately 5 per cent over the baseline grid. Note that for the cavity calculations, the solutions were tripped at the laminar flow reattachment point on the downstream lip.

Figure 22 shows laminar and turbulent results at wind tunnel conditions (with and without a cavity) normalized to the Fay-Riddell stagnation value. For a close-up of these laminar results in the vicinity of the cavity, see Figure 13. At these conditions. there is insufficient energy to drive the algebraic model to produce fully turbulent flow when tripped on the smooth body. In addition, the turbulent heating levels are quite different with and without the cavity at these conditions. 


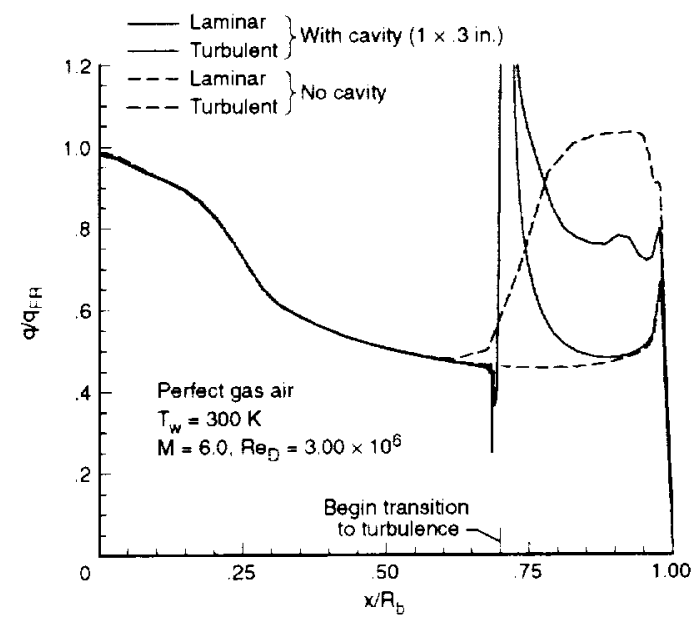

Figure 22. Computed laminar and turbulent centerline heating distributions at wind tunnel conditions.

Figure 23 provides a comparison between turbulent computations at wind tunnel conditions and the experimental results. At this Re, the cavity serves as an effective trip and the flow downstream of the cavity appears to approach fully turbulent levels. The agreement between the CFD results with a cavity and the wind tunnel data is not very good downstream of the cavity. This would appear to be a problem with the algebraic turbulence model in the presence of this complicated flow feature. Specifically, the ability to resolve the vortical flow emanating from the cavity, the applicability of the turbulence model (a modified flat-plate relation), and the appropriateness of the simple transition model are questionable. In reality, the turbulence levels over the smooth forebody are more in line with the wind tunnel data (see Figure 22 at a similar condition). As a result.

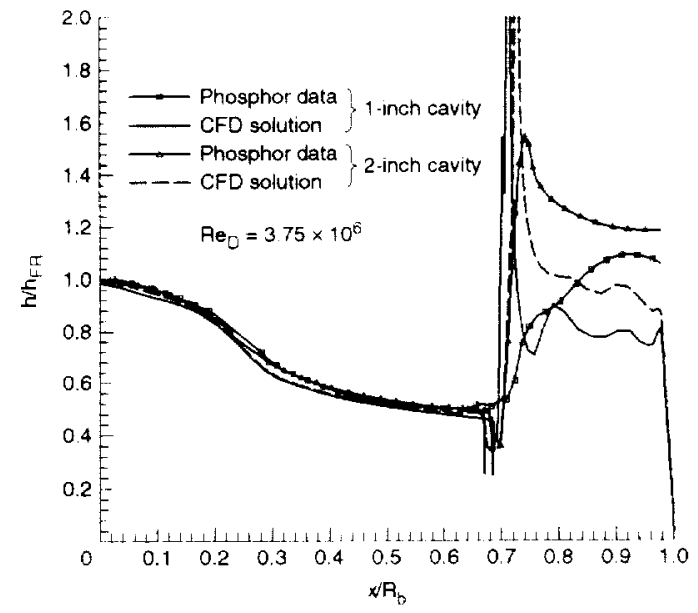

Figure 23. Comparison of phosphor line cuts with turbulent computations ( $\alpha=0 \mathrm{deg})$. smooth forebody calculations will be used to estimate the turbulent heating at flight conditions.

Figure 24 presents laminar and turbulent results at flight conditions. with and without a cavity. The laminar results are from Figure 9. At these conditions, the flow is sufficiently energized to yield fully turbulent flow downstream of the specified trip. Even with the cavity, there is sufficient energy to drive the turbulence model and produce nearly fully-turbulent heating values. Still, the smooth forebody computations provide a more conservative value. and will be used in later heat load calculations.

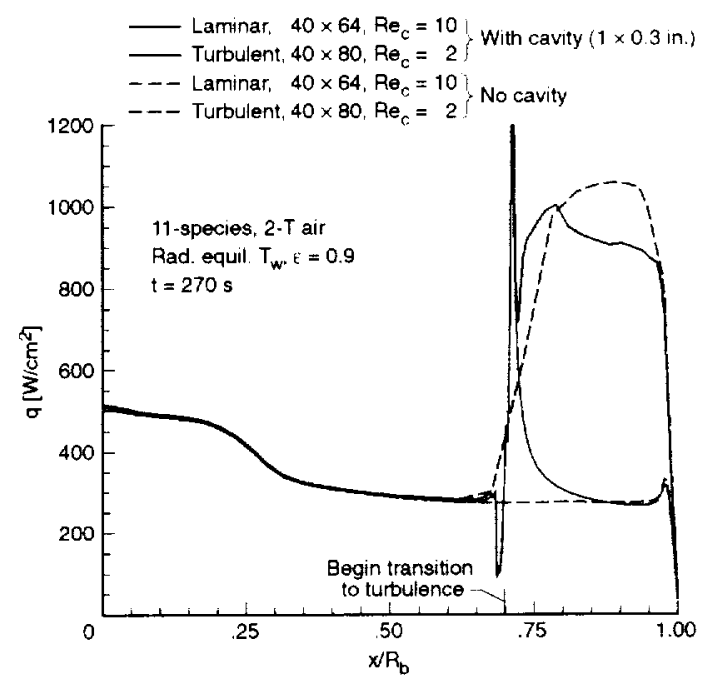

Figure 24. Computed laminar and turbulent centerline heating distributions at flight conditions.

\section{Integrated Heat Load}

Carbon-carbon is the forebody heat shield material for Genesis. The selection of heat shield material is driven by the estimated peak heating rate for the trajectory. Typically, this peak level occurs at the stagnation point when the freestream value of $\mathrm{pV}^{3}$ is at its maximum for the trajectory. The heating rate at the stagnation point is presented in Figure 25 and Table 5 as a function of time along the nominal trajectory. Also presented are laminar and turbulent values at the cavity location. Due to the presence of the penetrations, the maximum heating rate for Genesis is located downstream of the cavities. The heating rates are two to three times as large as the peak stagnation value but still within the capabilities of carbon-carbon.

The thickness of the heat shield for a given material is driven by the estimated heat load. The heat load 
at any point on the body is integrated area under the heat pulse as shown in Figure 25. The computed heat load at the stagnation point is. The corresponding laminar heat load at the cavity is $Q=9155 \mathrm{~J} / \mathrm{cm}^{2}$. In order to assess the sensitivity of the heat load at the cavity to the prescribed transition point, a number of additional CFD solutions were generated (see Figure 25). Assuming the flow is laminar at the cavities through peak heating $(t=270 \mathrm{~s})$ and transitions to fully turbulent by peak dynamic pressure $(t=280 \mathrm{~s})$ gives $Q=16580 \mathrm{~J} / \mathrm{cm}^{2}$ (essentially the stagnation value). A heat load based on instantaneous transition to turbulence at $t=270 \mathrm{~s}$ is calculated to be $Q=20.550 \mathrm{~J} / \mathrm{cm}^{2}(25$ per cent higher than the stagnation value).

The value of $\mathrm{Re}_{\leftrightarrow}$ at the cavity is included in Table 5 and Figure 25. Note that its value at $t=270 \mathrm{~s}$ is 194 . while at $t=280 \mathrm{~s}, \mathrm{Re}_{\mathrm{G}}=328$. Also note from Figure $2 \mathrm{l}$ that for a 1.0 -in cavity. the value of $w / \delta$ never exceeds 4 for the nominal trajectory. The wind tunnel data in closest proximity to the $t=270 \mathrm{~s}$ point on this figure is laminar, and there is no fully turbulent data below $w / \delta=7.0$. Given that wind tunnel flows traditionally transition earlier than free flight, a transition to turbulence aft of the cavity at $t=270 \mathrm{~s}$ seems reasonable. Further, the assumption of fully turbulent flow aft of the cavities at $\mathrm{t}=280 \mathrm{~s}$ would appear to be conservative. Thus, the current best estimate is that the heating aft of the cavities will produce an integrated heat load of the same magnitude $\left(Q=16580 \mathrm{~J} / \mathrm{cm}^{2}\right)$ as the stagnation value $\left(Q=16.770 \mathrm{~J} / \mathrm{cm}^{2}\right)$. In addition, the inherent conservatism of the wind tunnel, in conjunction with the conservative interpretation of the onset of turbulence, provides a safety factor for the heating environment downstream of the cavities.

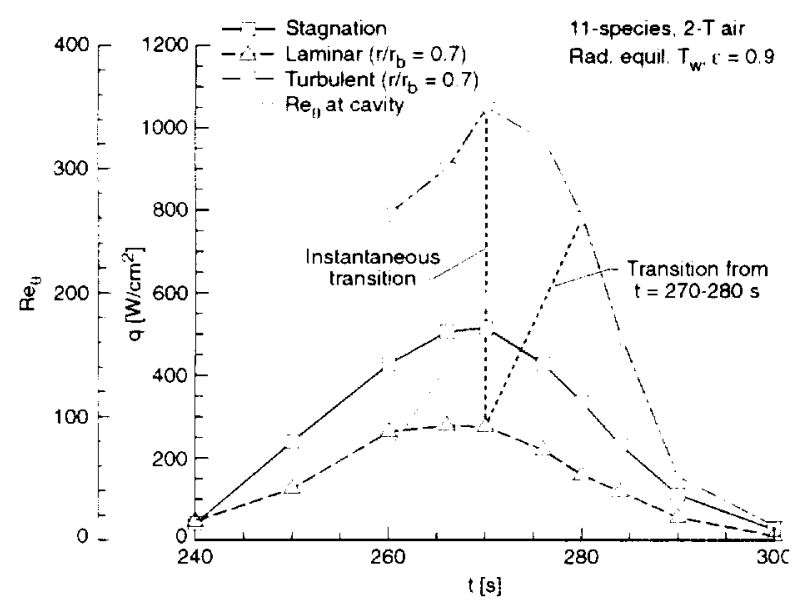

Figure 25. Computed heat load for nominal trajectory.
Table 5. Computed heating parameters along nominal trajectory.

\begin{tabular}{ccccc}
\hline \multirow{2}{*}[\mathrm{s}]{} & $\mathrm{x} / \mathrm{R}_{\mathrm{h}}=0$. & \multicolumn{3}{c}{$\mathrm{x} / \mathrm{R}_{\mathrm{h}}=0.7$} \\
\cline { 3 - 5 } & $\mathrm{q}\left[W / \mathrm{cm}^{2}\right]$ & $\mathrm{q}_{\operatorname{lam}}\left[W / \mathrm{cm}^{2}\right]$ & $\mathrm{q}_{\text {turh }}\left[W / \mathrm{cm}^{2}\right]$ & $\mathrm{Re}_{\mathrm{G}}$ \\
\hline 240 & 40 & 45 & & \\
250 & 240 & 125 & & \\
260 & 427 & 263 & 792 & 73 \\
266 & 506 & 278 & 903 & 140 \\
270 & 515 & 275 & 1050 & 194 \\
276 & 427 & 219 & 968 & 274 \\
280 & 335 & 159 & 783 & 328 \\
284 & 232 & 118 & 498 & 349 \\
290 & 111 & 55 & 155 & 359 \\
300 & 25 & 10 & & \\
\hline
\end{tabular}

\section{CONCLUDING REMARKS}

Cavities in the forebody heat shield of reentry capsules can produce heat spikes whose magnitudes are several times larger than the associated stagnation values. Such a cavity can also induce transition to turbulent flow downstream.

For blunt bodies, radial location of cavities has minimal impact on downstream heating levels because of limited running length. The radial location has a larger impact on the strength of the heat pulse, with stronger pulses occurring at the foremost positions.

If a cavity is small enough. no discernable heat pulse or turbulent transitioning is produced. Thus, from the standpoint of heating environment. multiple smaller penetrations are more desirable than fewer large holes.

The anticipated heating rates for the Genesis SRC fall within the capabilities of the carbon-carbon heat shield material. Based on the size and location of the forebody cavities, the traditional approach of sizing the heat shield to the expected stagnation point heat load should be adequate for the expected heating environment aft of the cavities.

\section{ACKNOWLEDGEMENTS}

The authors would like to thank the following individuals for their contributions to this effort: Steve Alter for volume grid generation: Tom Edquist and Doug Gulick of I.MA for laminar I.AURA solutions and discussions concerning forebody heating environments: and Harris Hamilton. Vince Zoby, and Peter Gnoffo for their insight into viscous hypersonic flow physics. 


\section{REFERENCES}

1. Desai, Prasun N.; Mitcheltree, Robert A.; and Cheatwood, F. McNeil: "Entry Trajectory Issues for the Stardust Sample Return Capsule"” Paper in International Symposium on Atmospheric Reentry Vehicles and Systems, Arcachon, France, March 16-18, 1999

2. Mitcheltree, Robert A.; Wilmoth, Richard G.; Cheatwood. F. McNeil; Brauckmann. G. J.: and Greene, Francis A.: "Aerodynamics of the Stardust Sample Return Capsule," J. Spacecraft \& Rockets. Vol. 36, No. 3, May-June. 1999, pp. 429-435.

3. Wilmoth, Richard G.; Mitcheltree, Robert A.: and Moss, James N.: "'Low-Density Aerodynamics of the Stardust Sample Return Capsule." J. Spacecraft \& Rockets, Vol. 36, No. 3, May-June. 1999. pp. $436-441$.

4. Olynick, David; Chen, Y-K: and Tauber, Michael E.: "Aerothermodynamics of the Stardust Sample Return Capsule," J. Spacecraft \& Rockets, Vol. 36. No. 3, May-June, 1999, pp. 442-462.

5. Desai, Prasun N.; Mitcheltree, Robert A.; and Cheatwood, F. McNeil: "Entry Dispersion Analysis for the Stardust Comet Sample Return Capsule," J. Spacecraft \& Rockets, Vol. 36, No. 3, May-June, 1999, pp. 463-469.

6. Desai, Prasun N. and Cheatwood, F. McNeil: "Entry Dispersion Analysis for the Genesis Sample Return Capsule," AAS Paper 99-469, AAS/AIAA Astrodynamics Specialist Conference, Girdwood, AK, August 16-19, 1999

7. Cheatwood, F. McNeil; Winchenbach, Gerald L.; Hathaway, Wayne; and Chapman, Gary: "Dynamic Stability Testing of the Genesis Sample Return Capsule," AIAA Paper 2000-1009, 38th AIAA Aerospace Sciences Meeting \& Exhibit. Reno, Nevada. January 10-13, 2000.
8. Desai, Prasun N.: Mitcheltree, Robert A.: and Cheatwood, F. McNeil: "Sample Return Missions in the Coming Decade," Paper IAF-00-Q.2.04. 51st International Astronautical Congress, Rio de Janeiro, Brazil, October 2-6, 2000.

9. Hunt, James L. and Jones, Robert A.: "Effects of Several Ramp-Fairing, Umbilical, and Pad Configurations on Aerodynamic Heating to Apollo Command Module at Mach," NASA TM X-1640, September 1968.

10. Creel, Theodore R., Jr.: "Experimental Investigation at Mach 8 of the Effects of Projections and Cavities on Heat Transfer to a Model of the Viking Aeroshell," NASA TM X-2941, April 1974.

11. Cheatwood, F. McNeil and Gnoffo, Peter A: "User's Manual for the Langley Aerothermodynamic Lipwind Relaxation Algorithm (LAURA)," NASA TM-4674, April 1996

12. Cheatwood, F. McNeil and Thompson, R.A.: "The Addition of Algebraic Turbulence Modeling to Program LAURA." NASA TM 107758, April 1993.

13. Merski, N. Ronald, Jr.: "An Improved Two-Color Relative-Intensity Phosphor Thermography Method For Hypersonic Wind Tunnel Aeroheating Measurements,"NASA CDTP-1017, February 2001 .

14. Nettelhorst, H. L. and Mitcheltree, Robert A: "Grid Resolution and Solution Convergence for Mars Pathfinder Forebody," NASA TM-109173. December 1994. 